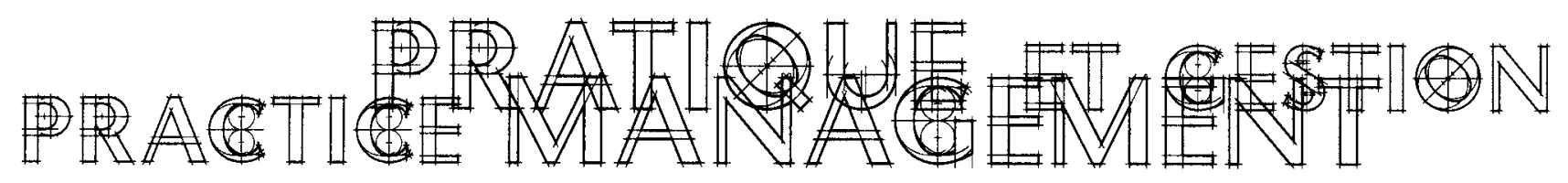

\title{
Benchmarking Simplified
}

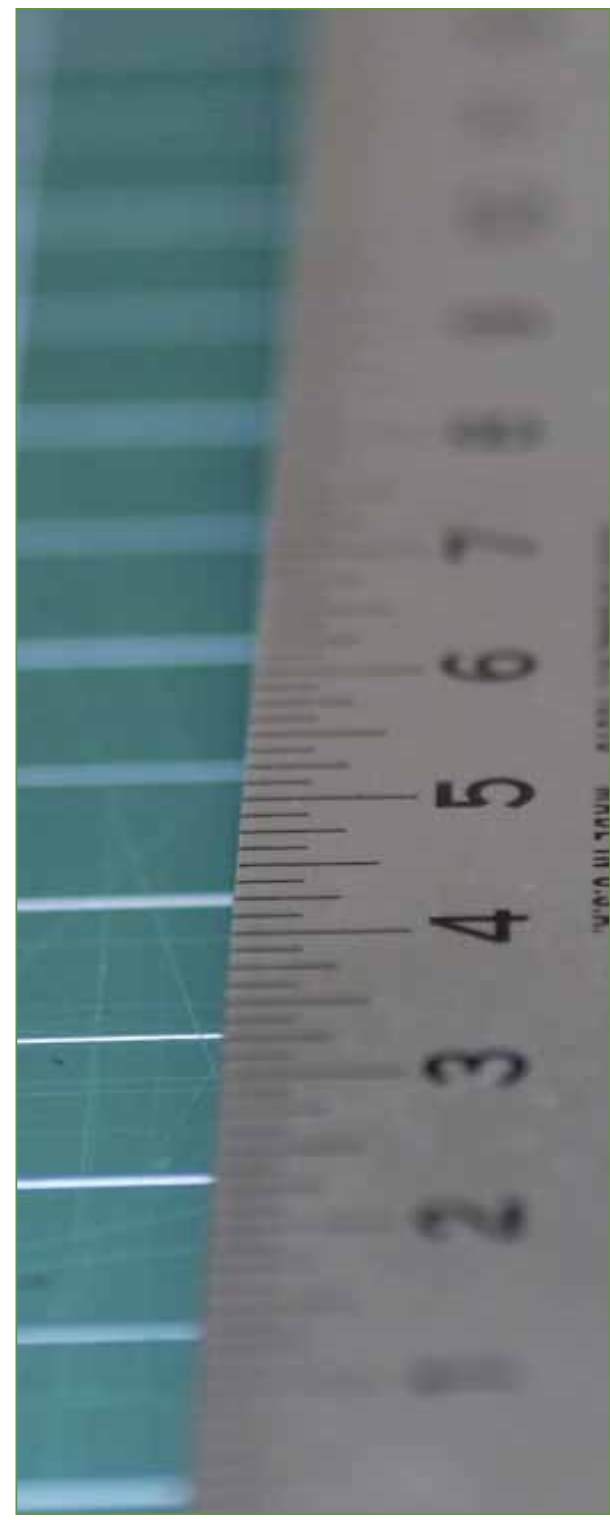

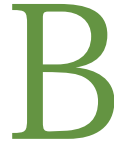

enchmarking the primary statistics of your practice and comparing your results to industry standards can be a solid management tool. As well, watching the trends of these statistics within your practice, over time, can show the effects of your management skills on the financial health of your practice.

These benchmarking techniques do not need to be cumbersome or complicated. You don't need to wait for a complete set of year-end fnancial statements. Make benchmarking a monthly routine just like reconciling your bank statement. Here's an easier way to do it.

To keep things simple there are primarily only 4 statistics that you need to collect: gross revenue, cost of goods sold (what you paid for frames, lenses and contact lenses), salary expense(excluding salaries paid to optometrists), general expenses and the last one, which you will calculate, is net income.

In optometric trade magazines there is often talk of separating rent as well but on an ongoing basis your rent factor (or occupancy costs) is a fixed expense and not something you can usually manage for change.

Often we pay our bills about a month after we incur the expense and recognize the revenue, but you will want to bring these expenses forward into the month where the revenue was made. For example if you pay your lab bill on July 15th then that bill should be recognized as a June expense. For the most part, that is when

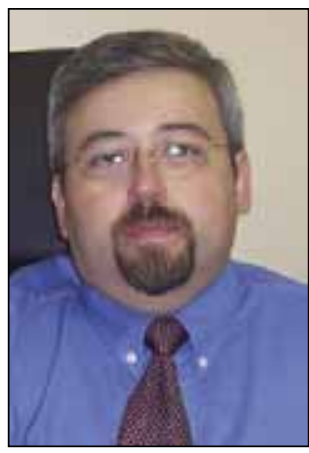

Alphonse Carew BSC, OD, MBA 


\section{PRACTICE MANAGEMENT PRATIQUE ET GESTION}

\begin{tabular}{|lrrrr|} 
& Month & Ratio & Year-to-Date & Ratio \\
Revenue & 30,000 & & 200,000 & \\
Cost of Goods & 10,000 & $33 \%$ & 60,000 & $30 \%$ \\
Salaries & 7,000 & $23 \%$ & 40,000 & $20 \%$ \\
Other Expenses & 5,000 & $17 \%$ & 36,000 & $18 \%$ \\
Net Income & 8,000 & $27 \%$ & 64,000 & $32 \%$ \\
\hline
\end{tabular}

you receive the revenue that caused that expense.

Once you have your expenses lined-up with your revenue you can then use a simple spreadsheet or table to calculate your major management statistics. Above is an example:

The ratios are calculated by simply dividing the item into your revenue figure. Determine your monthly figures along with your year-to-date figures for quick comparison.

If you track these five figures over time you'll start to see a pattern to the ratios.

For the "cost of goods" ratio you will notice that it stays fairly constant. In general, month over month you sell a consistent product mix to patients and the cost of these products stay at a consistent price. In the long run it would be beneficial to strike better deals with your suppliers in order to get your cost of goods ratio as low as possible and keep it there. This way more income will fall to your bottom line. For every percentage that you decrease this expense ratio your net income ratio will increase by the same amount. Once you negotiate these better deals, the positive effects on the profitability of your practice continue in high, and low, revenue months.

Salaries for most practices remain fairly constant from month to month; it can almost be considered a fixed expense. If we consider it a fixed expense then it becomes intuitive that in high revenue months your salary ratio will be low, the opposite will be true in low revenue months, there is a seesaw effect. So how can you manage this? Assuming that you have the proper number, and mix, of staff the only thing you can really do is strive to keep your gross revenue high and growing. Staff incentive programs can be of great benefit in helping attain higher revenue. If you have part-time employees you can sometimes cut back on staff in times when you know are historically slow, like Christmas.

Other general expenses will vary from month to month, so you will see this ratio fluctuate considerably. The comparison to the year-to-date figure can be helpful. If your average has been say $18 \%$ but one month is this ratio is $25 \%$ then it should send up a flag and you should look more closely to see what expenses caused the spike. Perhaps some purchases should be scheduled at other, busier times. Keeping a close watch on how the pennies are spent in the office can greatly help the bottom line.

The final ratio, the net income ratio, is obviously the most important one to consider for this is what the doctors get to take out of the practice. You calculate this ratio by factoring in the revenue, cost of goods, salaries and general expense figures. Net income is simply a byproduct of how you manage these. There is nothing you can do to directly effect net income, it is derived from the trade-off of expenses and revenue. Manage these well, and better net income will result.

O ne general statement that should be obvious is that all these ratios improve with better gross revenue.

To complete this analysis you may want to compare your monthly and year-to-date figures with industry standards. These are not absolute figures but historical data puts the cost of goods ratio at about $29 \%$ to $31 \%$, the salary ratio $18 \%$ to $21 \%$, and net income at about $30 \%$ to $32 \%$. Keep in mind these are averages and who really wants just an average practice!

\section{YOUR EYES DESERVE AN OPTOMETRIST}

Support the EHCC Partners that support our message.

For a full list of EHCC 2007 Partners, please visit the CAO member website.

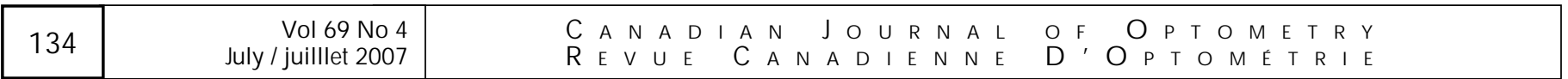

